\title{
O Desenvolvimento da Produção de Termos Relativos a Espaços em Crianças e Adultos
}

\author{
The Development of Terms Relating to Space in Children and Adults
}

\author{
Maria da Graça Bompastor Borges Dias*, Maria Laetitia Dantas Boudoux Silva, \\ Lisandra Mendonça de Carvalho, \& Fabiana Maria Lopes Haluli \\ Universidade Federal de Pernambuco
}

\begin{abstract}
Resumo
Em três estudos objetivou-se determinar quando crianças (de escolas públicas e particulares), universitários e adultos (que haviam cursado até a 5. ${ }^{a}$ série do ensino fundamental) começam a expressar apropriadamente termos relativos a espaços. Foram verificados "no(a)/em cima de", "no(a)/dentro de", "tirando de", "tirando de dentro", "dentro" e "fora". Os resultados mostram, nas questões referentes à localização dos objetos, que a produção e a apropriação dos termos relativos a espaço melhoram com o aumento da idade. O tipo de escola não interferiu nos resultados. Entretanto, nas questões relativas aos diferentes usos apropriados ou não dos termos, tanto a idade quanto o tipo de escolaridade influenciaram no desempenho das crianças. Nos adultos, apenas na Questão 2 do 2. ${ }^{\circ}$ Estudo houve influência do nível de escolaridade: os universitários obtiveram melhor desempenho do que aqueles que cursaram até a 5 . $^{\text {a }}$ série do ensino fundamental.

Palavras-chave: Termos relativos a espaços; desenvolvimento da linguagem; domínio semântico.
\end{abstract}

\begin{abstract}
In the three studies here described we aimed at determining when children (form public and private schools), college students and adults (who had completed the $5^{\text {th }}$ grade) begin to appropriately use terms that refer to space. The terms we investigated were "on" or "on the top of", "in" or "inside of", "taking off”, ' "taking out", "inside" and "outside". The results from the children show that, for questions regarding the placement of objects, the production and appropriation of spatial terms increase with age. The type of school had no effect on these results. However, we found that age and type of school had influenced the results among children for questions related to other uses of spatial terms. Comparisons between the two adult groups showed an effect of schooling in question 2 of the second study only, with college students outperforming adults with a $5^{\text {th }}$ grade education.
\end{abstract}

Keywords: Spatial terms; language development; semantic domain.

Em três estudos objetivou-se determinar quando crianças (de escolas públicas e particulares), universitários e adultos (que haviam cursado até a $5 .^{\text {a }}$ série do ensino fundamental) começam a expressar apropriadamente termos relativos a espaços. A seguir, os mesmos são descritos.

\section{1. ${ }^{\circ}$ Estudo}

A partir dos estudos de Piaget (1954) que mostram crianças bem novas estruturando a compreensão básica do mundo, muito antes de começarem a falar, a idéia de que a linguagem poderia influir nos primeiros conceitos adquiridos foi deixada para trás.

O estudo do desenvolvimento lingüístico estava baseado em pressupostos do behaviorismo (modelação, imitação e reforço) e em análises distributivas que focavam as formas lingüísticas e os invariantes da sintaxe. O significado era pouco explorado. Só nos anos 1970 surgiu a hipótese de que a aquisição da linguagem era influenciada pelas categorias cognitivas não lingüísticas das crianças.

*Endereço: UFPE, Departamento de Psicologia, Av. Acadêmico
Hélio Ramos, Cidade Universitária, 50670901, Recife, PE. mgbbdias@yahoo.com.br
Em estudos anteriores à década de 1970, quando crianças produziam termos espaciais erroneamente, pesquisadores argumentavam que estes termos seriam diretamente associados aos conceitos espaciais que surgem universalmente devido ao desenvolvimento cognitivo não lingüístico. No entanto, como discute Bowerman e Choi (2001, p.505) "comparações lingüísticas transculturais mostram que os padrões de extensão das crianças não convergem em um conjunto uniforme de categorias", como veremos mais adiante na descrição dos resultados obtidos por Choi e Bowerman (1991) com crianças falantes do inglês e do coreano.

Os primeiros trabalhos comparando a aquisição da linguagem entre crianças aprendizes de diversas línguas procuraram averiguar o que seria universal e o que seria específico de cada língua (ver Brown, 1973; Slobin, 1973). Acharam que em todas as línguas as primeiras sentenças das crianças tentavam solucionar um conjunto restrito de significados envolvendo intervenção, ação, possessão, locação, existência, reaparição, não existência e desaparecimento de objetos (Bowerman, 1976; Braine, 1976; Brown, 1973; Slobin, 1970, 1973). Estes resultados já 
haviam sido encontrados por Piaget (1954) quando descreveu os tipos de significados do desenvolvimento conceitual nos dois primeiros anos de vida (estágio sensóriomotor).

Para Bowerman e Choi (2001, p.476):

Longe de ser arbitrárias, as categorias semânticas da linguagem parecem refletir apenas os tipos de conceitos que são salientes não lingüisticamente aos seres humanos. É mais provável que elas (as crianças) tragam seus próprios conceitos para a tarefa de aprendizagem da linguagem e tentem aprender como codificá-los.

Outro argumento que vem sustentar esse ponto de vista sobre os tradicionais modelos de formação de conceito, é trazido por Nelson (1974, p.268). Para o autor, a questão básica de "Como a criança forma um conceito para encaixar a palavra?”, deveria ser feita ao contrário "Como a criança combina palavras para seus conceitos?”.

Bowerman e Choi (2001, p.477) optam por uma posição mais interativa, sugerindo que o começo do desenvolvimento semântico envolve a “interação entre desenvolvimento conceitual não lingüístico e categorias semânticas da linguagem, não apenas um mapeamento em um só sentido do conceito preexistente". Bowerman (2000, pp.199-200) vai mais além, depois de analisar vários estudos transculturais de aquisição da linguagem, concluindo que:

\begin{abstract}
...apesar do desenvolvimento cognitivo não lingüístico oferecer uma fundação indispensável para o desenvolvimento semântico, seu papel é menos direto do que tem sido previsto freqüentemente. Diferentes línguas organizam significados em maneiras diferentes. Isto significa que a organização semântica de uma língua em particular faz tanto parte da estrutura a ser dominada como fazem a sintaxe e a morfologia da língua. Em lugar de simplesmente combinar palavras aos conceitos preexistentes, os aprendizes retiram seus recursos conceptuais para ajudá-los a determinar como sua língua estrutura o conteúdo para ser expressado.
\end{abstract}

Pergunta-se e quanto ao desenvolvimento da compreensão de palavras para designar espaço?

Para Piaget e Inhelder (1956) e Gibson e Spelke (1983), as crianças representam e interpretam o espaço muito antes de começar a falar sobre ele. Behl-Chadha e Eimas (1995) mostram que bebês com poucos meses de nascidos são capazes de distinguir entre cenas e categorizá-las com base em informação espacial como direita-esquerda. Os bebês também sabem que um objeto não pode passar dentro do outro (Spelke, Breinlinger, Macomber \& Jacobson, 1992). Para E, segundo Needham e Baillargeon (1993), o bebê entende que se soltar um objeto no ar o mesmo irá cair.

Perguntamos agora sobre o desenvolvimento da aquisição apropriada de palavras para designar espaço.

Em vários estudos transculturais, Bowerman e colaboradores (Bowerman, 1996; Bowerman, de Léon \& Choi, 1995; Choi \& Bowerman, 1991) encontraram que:

- Crianças inglesas e coreanas começam a utilizar apropriadamente palavras para designar espaço entre $14 \mathrm{e}$
20 meses. Estas palavras são, p. ex., referentes a colocar e tirar roupas, abrir e fechar depósitos, colocar algo dentro e tirar etc;

- As crianças inglesas começam espontaneamente a utilizar partículas ou preposições, como p. ex., up, down, on, off, in, out e back e verbos tais como open e close. Já as crianças coreanas utilizam verbos para categorizar ações de colocar um objeto em contato com outro;

- As inglesas utilizam as partículas para espaço, tanto para movimentos espontâneos como para movimentos induzidos, p. ex.: in, para entrar em uma banheira ou colocar um retrato na parede; up, quando tentam subir em uma cadeira ou como um pedido para serem carregadas; on, para colocar um copo na mesa, um chapéu na cabeça, um anel no dedo, etc; e, usam in para colocar um objeto em algum depósito, caixa, isto é, para colocar uma maçã na tigela, uma fita de vídeo dentro de sua caixa ou um livro dentro de uma sacola grande;

- Já as coreanas utilizam diferentes verbos, como p. ex., um para colocar um copo na mesa, outro para colocar um chapéu na cabeça. Utilizam um tipo de verbo para colocar algo em uma caixa que envolva o mesmo, de modo que fique bem encaixado: colocar um anel no dedo ou uma fita de vídeo dentro de sua caixa. E utilizam outro verbo para colocar objetos em depósitos bem maiores que os mesmos: uma maçã em uma tigela, um livro dentro de uma sacola grande.

Resumindo, as crianças inglesas estabelecem um "conjunto uniforme de categorias que abstraem de como o movimento ocorre, enquanto as crianças que aprendem coreano precisam distinguir meticulosamente entre movimentos espontâneos e causados e dominam dois conjuntos de categorias que freqüentemente não coincidem" (Bowerman \& Choi, 2001, p.487).

Os estudos de Bowerman e Pederson (1992) com falantes de 36 línguas, entre eles japoneses, holandeses, hebraicos, húngaros, objetivaram investigar como as crianças distinguiriam situações de suporte, de conter, envolver, ligar, perfurar, pendurar objetos, etc. As inglesas usam on para copo na mesa (a), bandaid na perna (b), quadro na parede (c), maçaneta na porta (d), maçã no galho (e), e in para maçã na tigela (f). As distinções encontradas entre as diversas línguas são bastante significativas. P. ex., em holandês, estas seis situações têm três termos distintos. Um para (a) e (b); outro para (c), (d) e (e); e outro para (f). As autoras concluem que:

...o que uma língua considera como apoio ou inclusão não é dada pela estrutura da realidade ou nossa percepção sobre ela, mas é determinada por uma extensão das convenções específicas da linguagem de como cenas espaciais são construídas. Essas convenções, é claro, são aprendidas. O aprendizado poderia, no entanto, ser facilitado se crianças fossem implicitamente guiadas em suas generalizações por um senso de similaridade entre as situações espaciais (Bowerman \& Choi, 2001, p.487).

Os resultados dos estudos das autoras refletem a fala espontânea nos primeiros estágios do desenvolvimento semântico. É necessária uma comparação mais direta, e/ou experimental com falantes do português. Mesmo tendo em 
vista que as crianças de 2 anos possuem limitações de linguagem, optamos por entrevistá-las com o objetivo de verificar os primeiros indícios da aquisição apropriada de termos espaciais.

Assim, o objetivo do primeiro estudo foi verificar como crianças e adultos brasileiros falantes do português descrevem conjuntos de objetos que representam categorias espaciais específicas desta língua. Os adultos foram incluídos a fim de que houvesse um parâmetro de comparação das variações entre a linguagem adulta e das crianças falantes do português como também verificar o papel do nível de escolarização na aquisição dos termos espaciais. Como sabemos, na língua portuguesa, o termo on é traduzido como “no/na” ou "em cima” e não como "dentro". Já o termo in é traduzido também como "no/na” ou "dentro" e não como "em cima”. A importância de estudar conceitos espaciais apóia-se no fato de que eles, como argumenta Talmy (1976), proporcionam os princípios estruturais não só para a linguagem espacial, mas para outros domínios semânticos, tais como tempo, causalidade e mudança de situação.

\section{Método}

\section{Participantes}

A amostra foi composta por 60 crianças de escolas públicas e particulares, sendo 30 de cada tipo de escola, das quais 20 com idade média de 2 anos e 6 meses (2-2,11), 20 de 3 anos e 6 meses $(3-3,11)$ e 20 de 4 anos e 6 meses $(4-4,11)$. Também foram entrevistados 20 estudantes universitários e 20 adultos que tinham cursado até a $5^{\text {a }}$ série do ensino fundamental, para uma melhor compreensão a respeito da expressão de termos relativos a espaço.

\section{Material}

Vários conjuntos de dois objetos adaptados dos utilizados por Choi e Bowerman (1991).

\section{Procedimento}

Cada conjunto de dois objetos foi apresentado à criança/ adulto, individualmente, e em ordem randômica. O experimentador (E) mostrava cada par separado e perguntava, gesticulando como se fosse, p. ex., no caso de uma mesinha e um copo, colocar o copo na mesa: "O que posso fazer com (diz o nome dos objetos). Diga o que eu estou fazendo". Esse tipo de questão, utilizada por Bowerman e Choi (1994), Bowerman (1996) e por Choi (1997), é bem compreendida mesmo por crianças de 2 anos de idade. Após o participante verbalizar a expressão "colocar/botar" na mesa (Questão 1), perguntava-se, caso tivesse sido utilizada a sentença "colocar, botar dentro/em cima da/ou na mesa", qual seria a "mais certa" ou se "as duas estariam certas" (Questão 2). O mesmo acontecia quando uma laranja era posta dentro de uma tigela.

\section{Resultados e Discussão}

As respostas corretas oferecidas pelas crianças, tanto na primeira questão quanto na segunda (ver Tabela 1) foram comparadas com uma Análise de Variância para medidas repetidas, tendo como fatores Idade (3), Tipo de Escola (2) e como Variável Dependente o número de respostas corretas para a primeira questão e para a segunda questão. O mesmo tipo de análise foi realizado com os adultos.

As análises estatísticas demonstram um efeito significativo para Idade na Questão $1[\mathrm{~F}(2,54)=7,13, p<0,002]$ e na Questão $2[\mathrm{~F}(2,54)=5,10, p<0,01]$. Para Tipo de Escola houve efeitos significativos para a Questão $1[\mathrm{~F}(1,54)=9,51$, $p<0,003]$ e para a Questão $2[\mathrm{~F}(1,54)=24,25, p<0,001]$, tendo sido sempre maior o número de respostas corretas oferecidas pelas crianças de escolas particulares quando comparadas àquelas de escolas públicas/creches.

Foi aplicado o pós-teste de Newman-Keuls que mostrou, na Questão 1, que as crianças de 4 anos obtiveram um número significativamente maior de respostas corretas do que as de $2 \operatorname{anos}(p=0,01)$. Todas as outras comparações entre as idades foram não significativas. Na Questão 2, o pós-teste demonstrou o mesmo resultado: as crianças de 4 anos obtiveram maior média de acertos do que as de 2 anos $(p=0,01)$.

Quanto aos adultos (Ver Tabela 2), a Anova não denotou efeito significativo nem para a Questão $1[\mathrm{~F}(1,38)=1$, 00 , $p<0,32]$, nem para a Questão $2[\mathrm{~F}(1,38)=1,83, p<0,20]$.

A produção dos termos "colocar dentro" e "colocar em cima" já é diferenciada aos 2 anos de idade como ocorre também com as crianças inglesas, o que foi indicado nos estudos com a fala espontânea de Bowerman et al. (1995). No entanto, entre 3 e 4 anos de idade é que as crianças têm domínio dos mesmos, principalmente as que freqüentam escolas particulares, apesar de, como argumentado no procedimento, Bowerman et al. terem encontrado que crianças mesmo de 2 anos de idade não apresentavam dificuldades em questões do tipo 1. Quanto aos adultos, o grau de instrução parece não interferir na produção destes termos.

\section{2. ${ }^{\circ}$ Estudo}

Clark (1973) argumenta que a habilidade para perceber e representar as relações espaciais pode ser considerada como fundamental à vida humana. Esta habilidade tem

Tabela 1

Médias de Acertos Obtidas pelas Crianças em cada Questão em Função da Idade e do Tipo de Escola (1. ${ }^{\circ}$ Estudo)

\begin{tabular}{ccccc}
\hline Idades & \multicolumn{2}{c}{ Escolas Particulares } & \multicolumn{2}{c}{ Escolas Públicas e Creches } \\
\hline \multirow{4}{*}{2 anos } & Questão 1 & Questão 2 & Questão 1 & Questão 2 \\
\cline { 2 - 5 } & 2,90 & 1,80 & 2,40 & 1,60 \\
3 anos & $(1,10)$ & $(1,48)$ & $(1,35)$ & $(1,08)$ \\
& 3,80 & 3,10 & 2,60 & 1,50 \\
4 anos & $(0,42)$ & $(0,88)$ & $(1,35)$ & $(0,71)$ \\
& 4,00 & 3,70 & 3,50 & 1,70 \\
& $(0,00)$ & $(0,49)$ & $(0,53)$ & $(1,06)$ \\
\hline Total & 3,57 & 2,86 & 2,83 & 1,60 \\
\hline
\end{tabular}

\section{Tabela 2}

Médias de Acertos Obtidas pelos Adultos em cada Questão em Função do Nível de Escolarização $\left(1 .^{\circ}\right.$ Estudo)

\begin{tabular}{cccc}
\multicolumn{4}{c}{ Função do Nivel de Escolarização $\left(1 .^{\circ}\right.$ Estudo) } \\
\hline Universitários & A té a $5 .^{\text {a }}$ série do ensino fundamental \\
\hline Questão 1 & Questão 2 & Questão 1 & Questão 2 \\
\hline 4,00 & 3,75 & 3,95 & 3,45 \\
$(0,00)$ & $(0,44)$ & $(0,22)$ & $(0,89)$ \\
\hline
\end{tabular}


apoio da visão, de outros sistemas biológicos, de fatores universais fisiológicos e ambientais, como por exemplo, postura vertical, assimetria frente-atrás e gravidade.

Bowerman (1978) e Clark (1973) encontraram que certas palavras, também para designar espaço como open, são aplicadas em outras situações. Exemplos desta categoria podem advir da palavra "abrir". As crianças utilizam open para manipular janelas, portas e depósitos e também para tirar uma peça de um quebra-cabeça e para ligarem uma máquina de escrever elétrica.

Em estudo longitudinal com crianças de 1 a 3 anos aprendendo inglês ou coreano como língua materna, que objetivou investigar a fala espontânea das mesmas sobre espaço, Choi e Bowerman (1991) encontraram que todas as crianças participantes começam a falar sobre espaço entre 14 e 16 meses. Diante de situações novas, as crianças entre 16 e 20 meses conseguem utilizar palavras que designam espaço apropriadamente. Falas espontâneas tais como: colocar/tirar roupa ou objetos, abrir/ fechar depósitos, sentar-se/levantar-se.

No entanto, estes dados fornecem um panorama da "fala espontânea” mesmo que os pesquisadores introduzissem contextos novos quando em interação com as crianças. Essa reflete diferentes situações sobre o que cada criança quer falar. Para uma comparação mais direta, faz-se necessário um estudo no qual se utilizem conjuntos de objetos padrões para serem manipulados.

Assim, o objetivo deste segundo estudo foi verificar o desenvolvimento da produção apropriada de palavras "tirando de" (taking off) e "tirando de dentro" (taking out) de diferentes tipos de depósitos, superfícies, etc.

A idade das crianças que participaram variavam entre 2 anos a 4 anos e 11 meses, em virtude das tarefas terem sido consideradas difíceis em um estudo piloto realizado com crianças mais novas (14-20 meses). Também foram entrevistados adultos, como no $1 .^{\circ}$ estudo.

\section{Método}

\section{Participantes}

A amostra foi composta por 60 crianças de escolas públicas e particulares, sendo 30 de cada tipo de escola, das quais 20 com idade média de 2 anos e 6 meses (2-2,11), 20 de 3 anos e 6 meses $(3-3,11)$ e 20 de 4 anos e 6 meses $(4-4,11)$. Também foram entrevistados 20 estudantes universitários e 20 adultos que tinham cursado até a $5^{\text {a }}$ série do ensino fundamental, para uma melhor compreensão da expressão de termos relativos a espaço.

\section{Material}

Vários conjuntos de dois objetos adaptados dos utilizados por Choi e Bowerman (1991).

\section{Procedimento}

O examinador apresentava a cada participante, individualmente, cada par de objetos e fazia um gesto, como se fosse, p. ex., tirar a tampa de uma panela. Perguntava, então: "Diga-me o que estou fazendo" (Questão 1). No caso do participante verbalizar "Tirando a tampa da panela”, o examinador perguntava "Tirando da panela, de dentro da panela ou os dois estão certos?” (Questão 2). O mesmo ocorria quando era mostrada uma fruta dentro de uma tigela.

\section{Resultados e Discussão}

Pode-se observar na Tabela 3 que a média de acertos aumenta com a idade, o que era esperado, independentemente da questão e do tipo de escola.

Como no estudo anterior, foi realizada uma Análise de Variância tendo como fatores Idade e Tipo de Escola e como Variável Dependente o número de acertos em cada uma das questões. Esta análise para a Questão 1 mostrou um efeito significativo para Idade $[\mathrm{F}(2,54)=21,46, p<0,001]$. Para o Tipo de Escola não houve diferença significativa nesta questão $[\mathrm{F}(1,54)=0,03, p=0,85]$. As médias de acertos em cada idade dos dois tipos de escola foram comparadas, utilizando-se o teste de Newman-Keuls. O teste mostrou que as crianças de 3 e 4 anos têm significativamente melhor desempenho do que as de $2 \operatorname{anos}(p<0,01)$. Não há diferença significativa na média de acertos entre as crianças de 3 e 4 $\operatorname{anos}($ p.n.s.).

A análise realizada para a Questão 2 denota efeito significativo para Idade $[\mathrm{F}(2,54)=11,38, p<0,001]$ e para o Tipo de Escola $[\mathrm{F}(1,54)=6,23, p<0,02]$. Para comparação das médias de acertos foi utilizado o pós-teste de NewmanKeuls. Esse denotou que as crianças de 4 anos obtiveram médias de acertos significativamente maiores do que as de 2 $\operatorname{anos}(p<0,01)$ e de $3 \operatorname{anos}(p<0,05)$.

Na Questão 1, o desempenho das crianças de escolas públicas e creches não diferiu daquele das crianças de escolas particulares. Na Questão 2, as crianças de escolas particulares obtiveram significativamente maior número de acertos do que as crianças de escolas públicas e creches.

Quanto aos adultos, pode-se observar a partir dos dados apresentados na Tabela 4, que na Questão 1 não houve diferença significativa de acertos entre os dois grupos de participantes $[F(1,38)=1,05, p=0,31]$. Porém, na Questão 2 , os universitários obtiveram um desempenho significativamente melhor do que o outro grupo $[\mathrm{F}(1,38)=4,34, p<0,044]$.

No estudo com a fala espontânea realizado por Choi e Bowerman (1991), crianças de 16 a 20 meses já conseguiam utilizar os termos "tirar de" e "tirar de dentro". No presente

Tabela 3

Médias de Acertos Obtidos pelas Crianças em cada Questão em Função da Idade e do Tipo de Escola (2 Estudo)

\begin{tabular}{lcccc}
\hline \multicolumn{2}{c}{ Idade (anos) } & \multicolumn{2}{c}{ Escolas Particulares } & \multicolumn{2}{c}{ Escolas Públicas e Creches } \\
& Questão 1 & Questão 2 & Questão 1 & Questão 2 \\
\hline 2 & $0,90(1,37)$ & $0,20(0,42)$ & $0,30(0,67)$ & $0,00(0,00)$ \\
3 & $2,80(1,75)$ & $0,80(0,79)$ & $3,10(1,37)$ & $0,60(0,51)$ \\
4 & $3,00(1,70)$ & $2,20(1,93)$ & $3,50(1,27)$ & $0,80(0,63)$ \\
Total & 2,23 & 1,06 & 2,30 & 0,46 \\
\hline
\end{tabular}


Tabela 4

Médias de Acertos Obtidos pelos Adultos em Função do Nível de Escolaridade (2o Estudo)

\begin{tabular}{llll}
\hline \multicolumn{2}{l}{ Universitários } & \multicolumn{2}{c}{ Até $5^{a}$ série do ensino fundamental } \\
\hline Questão 1 & Questão 2 & Questão 1 & Questão 2 \\
$3,95(0,22)$ & $3,95(0,22)$ & $3,80(0,62)$ & $3,35(1,27)$ \\
\hline
\end{tabular}

experimento, na Questão 1, aos 2 anos o desempenho ainda foi baixo. No entanto, aos 3-4 anos, independente do tipo de escola, a performance das crianças melhorou bastante.

Na Questão 2, na qual era perguntado qual dos termos era mais apropriado ou se ambos os termos eram certos, não utilizada nos estudos de Choi e Bowerman (1991), as crianças de 4 anos de escolas particulares obtiveram média de acertos acima das mais novas e daquelas da mesma idade de escolas públicas. O fator grau de escolarização teve efeito significativo nos adultos.

\section{3. ${ }^{\circ}$ Estudo}

Neste terceiro estudo, continuamos a investigar o domínio de termos relativos a espaço, a fim de explorar variações semânticas entre diferentes idades, tipos de escola e grau de escolarização.

Os estudos transculturais de vários pesquisadores (Ex.: Johnston, 1985; Sinha, Thorseng, Hayashi \& Plunkett, 1994) denotam que a ordem de aquisição de palavras para designar espaço pelas crianças é, relativamente, a seguinte:

1- Morfemas para noções de inclusão (in), suporte (on) e oclusão (under);

2- Morfemas para proximidade (next to, beside, between);

3- Morfemas para relacionamentos projetivos (in front of, behind).

Em 1956, Piaget e Inhelder já haviam detectado esta mesma seqüência para conceitos espaciais através de tarefas não lingüísticas. Isto sugere, segundo Bowerman (2000, p.207), que «enquanto amadurecem os conceitos, as crianças procuram formas lingüísticas para expressá-las». Assim, o objetivo deste estudo foi investigar como crianças de diferentes tipos de escola e adultos de diferentes níveis de escolarização produzem os termos "dentro" (in) e "fora" (out), nas diferentes localizações de objetos em relação a outros.

\section{Método}

\section{Participantes}

A amostra foi composta por 60 crianças de escolas públicas e particulares, sendo 30 de cada tipo de escola, das quais 20 com idade média de 2 anos e 6 meses (2-2,11), 20 de 3 anos e 6 meses $(3-3,11)$ e 20 de 4 anos e 6 meses $(4-4,11)$. Também foram entrevistados 20 estudantes universitários e 20 adultos que tinham cursado até a $5^{\text {a }}$ série do ensino fundamental.

\section{Material}

Vários conjuntos de dois objetos adaptados dos utilizados por Choi e Bowerman (1991).

\section{Procedimento}

O examinador apresentou a cada participante, individualmente, cada desenho (Ex.: um brinquedo dentro de uma caixa). Em seguida, perguntava: "Onde está o brinquedo?" (Questão 1.1). No caso do participante verbalizar "na caixa", o examinador perguntava "na caixa ou dentro da caixa ou os dois estão certos?” (Questão 1.2). Depois, o examinador mostrou a situação inversa (Ex.: um brinquedo fora de uma caixa), perguntando, então: "Onde está o brinquedo?” (Questão 2.1). No caso da criança verbalizar "Está junto da caixa", o examinador perguntava: "Está junto da caixa ou está fora da caixa ou os dois estão certos?” (Questão 2.2).

\section{Resultados e Discussão}

$\mathrm{Na}$ Tabela 5 encontram-se as médias alcançadas pelas crianças de cada idade dos dois tipos de escola. Nota-se que as médias de acertos foram maiores nas crianças de escolas particulares do que nas de escolas públicas/creches. Observa-se também que as primeiras questões para "dentro" e "fora" foram sempre mais fáceis do que as segundas questões. Na maioria dos casos, a performance melhora com a idade.

A Análise de Variância que teve como fatores Idade e Tipo de Escola e como Variável Dependente a média de acertos em cada questão, mostrou efeito significativo para Idade na Questão $1.1[\mathrm{~F}(1,54)=16,58, p<0,001]$, na Questão $2.1[\mathrm{~F}(1,54)=17,38, p<0,001]$ e na Questão 2.2 $[\mathrm{F}(1,54)=5,82, p<0,02]$. Todos demonstrando que as crianças de escolas particulares obtêm significativamente mais acertos do que aquelas de escolas públicas.

As médias de acertos em cada idade das crianças dos dois tipos de escola foram comparadas com o teste de NewmanKeuls. Esse demonstrou que as crianças de 3 e 4 anos, independente do tipo de escola, têm um desempenho melhor do que as de 2 anos $(p<0,01)$. As crianças mais velhas não se diferenciam em suas performances.

Na Tabela 6 encontram-se os dados dos participantes adultos cuja Anova não denotou qualquer diferença significativa em cada uma das questões.

\section{Discussão Geral}

Em três estudos, verificamos a produção apropriada de termos relativos a espaço em crianças e em adultos. No $1 .{ }^{\circ}$ Estudo, o uso das palavras "no(a) ou em cima de" e "no(a) ou dentro de"; no segundo, a utilização de "tirando de" e "tirando de dentro de"; e no terceiro, o uso de "dentro" e “fora” em relação à localização de objetos.

Nos estudos com falas espontâneas de crianças falantes de inglês e coreano, Choi e Bowerman (1991) demonstraram o uso apropriado dos termos aqui estudados, a partir dos 16 a 20 meses de idade. Nos nossos estudos isso aparece mais tarde.

Como argumentado, nos estudos anteriores foi observada a fala espontânea das crianças, ou seja, o que essas queriam 
Tabela 5

Médias de Acertos Obtidos pelas Crianças em cada Questão em Função da Idade e do Tipo de Escola

\begin{tabular}{lcccccccc}
\hline Idades (anos) & \multicolumn{4}{c}{ Escolas Particulares } & \multicolumn{3}{c}{ Escolas Públicas e Creches } \\
\hline & Questão 1.1 & Questão 1.2 & Questão 2.1 & Questão 2.2 & Questão 1.1 & Questão 1.2 & Questão 2.1 & Questão 2.2 \\
2 & $3,20(1,13)$ & $1,60(1,51)$ & $2,50(1,96)$ & $1,60(1,78)$ & $0,70(1,06)$ & $0,10(0,32)$ & $0,10(0,32)$ & $0,00(0,00)$ \\
3 & $3,40(0,97)$ & $1,80(1,62)$ & $2,20(1,81)$ & $1,60(1,78)$ & $2,90(1,66)$ & $1,40(1,51)$ & $1,80(1,93)$ & $0,80(1,39)$ \\
4 & $4,00(0,00)$ & $1,60(1,71)$ & $3,80(0,42)$ & $1,70(1,57)$ & $3,70(0,67)$ & $2,20(1,99)$ & $1,50(1,96)$ & $1,20(1,93)$ \\
Total & 3,53 & 1,66 & 2,83 & 1,63 & 2,43 & 1,23 & 1,13 & 0,66 \\
\hline
\end{tabular}

Tabela 6

Médias de Acertos Obtidos pelos Adultos em Função do Nível de Escolaridade ( $3^{\circ}$ Estudo)

\begin{tabular}{lcccc}
\hline & Questão 1.1 & Questão 1.2 & Questão 2.1 & Questão 2.2 \\
\hline Universitários & $3,70(0,65)$ & $2,80(1,28)$ & $3,40(0,99)$ & $2,65(1,56)$ \\
Até 5a série do ensino fundamental & $3,60(0,75)$ & $2,20(1,15)$ & $3,45(1,05)$ & $1,90(1,62)$ \\
\hline
\end{tabular}

falar diante de diversas situações apresentadas. No nosso caso, as crianças eram argüidas sobre a localização de um objeto em relação ao outro, além de serem questionadas sobre os diferentes usos apropriados ou não dos termos aqui estudados. A questão lançada sobre o desenvolvimento da aquisição apropriada de palavras para designar espaço em uma comparação mais direta e/ou experimental, pode ser a explicação para a diferença encontrada no presente estudo.

Na observação da fala espontânea, Bowerman et al.(1995) encontraram que a produção dos termos "colocar dentro" e "colocar em cima” já é adequada aos 2 anos de idade. No nosso $1 .^{\circ}$ Estudo esta produção é adquirida um a dois anos após. Entre os adultos o grau de instrução não interferiu na produção destes dois termos.

Sem levar em consideração a Questão 2 do nosso 2. ${ }^{\circ}$ Estudo, crianças de 3-4 anos independentemente do tipo de escola (particular ou pública) utilizaram adequadamente os termos "tirar de" e "tirar de dentro de". Espontaneamente, como demonstra Bowerman et al. (1995), isso acontece entre $16 \mathrm{e}$ 20 meses de idade. Assim como foi observado no 1. ${ }^{\circ}$ Estudo, esta produção é adquirida um a dois anos após. Nos adultos, a produção destes termos ocorreu sem interferência do grau de instrução.

Similarmente no $3 .^{\circ}$ Estudo crianças de $3-4$ anos de idade, independentemente do tipo de escola, utilizaram os termos "no(a)/dentro de" ou "junto de/fora de" adequadamente, apresentando um melhor desempenho do que as de 2 anos de idade. A produção destes termos se deu de forma satisfatória nos adultos, independentemente do grau de instrução.

Portanto, no geral, para as questões referentes à localização dos objetos (primeiras questões dos três estudos), os resultados obtidos denotaram que a produção e apropriação dos termos relativos a espaço, nas crianças, melhora com o aumento da idade, o que era esperado.

O tipo de escola em vários estudos de desenvolvimento lingüístico (ver Dias, Morais \& Pessoa, 1995; Dias \& Vanderlei, 1999; Lins e Silva \& Spinillo, 1998, 2000; Spinillo \& Pratt, 2002) aparece como um fator de relevância, interferindo nos resultados: crianças de escolas particulares saem-se melhor do que as de escolas públicas. O mesmo foi observado em nossa investigação nas questões relativas aos diferentes usos apropriados dos termos (segundas questões dos três estudos), em que tanto a idade quanto o tipo de escolaridade foram fatores que tiveram influência no desempenho das mesmas.Quanto aos adultos, apenas na Questão 2 do 2. ${ }^{\circ}$ Estudo o nível de escolaridade influenciou nos resultados, isto é, os universitários obtiveram melhor desempenho do que aqueles que cursaram até a $5 .^{a}$ série do ensino fundamental.

Concluindo, apesar de vários estudos de Bowerman et al. demonstrarem que a compreensão de palavras para designar espaço e a aquisição apropriada destas palavras ocorrem em algumas línguas aos 2 anos de idade, inclusive em crianças falantes do espanhol (Bowerman \& Pederson, 1992), variações existem. Em situações experimentais, muitas tarefas podem levar ao desenvolvimento de certas habilidades, principalmente quando envolvem treinamento e/ou interação (ver Ceci \& Roazzi,1994; Moro, 1991; Roazzi, 1996; Roazzi \& Bryant, 1992). Na presente investigação não houve treinamento, o que é recomendado em estudos posteriores. Nossas crianças de 2 anos demonstraram um desenvolvimento restrito quanto à produção apropriada de termos relativos a espaços, apresentando melhor aquisição dos termos utilizados a partir dos 3 anos de idade. Foi possível verificar que o aperfeiçoamento destas habilidades é diretamente proporcional ao avanço na idade da criança. Observou-se também diferenças de desempenho quanto à compreensão de certos termos quando se comparava os Tipos de Escola, o que pode ser devido aos diferentes ambientes lingüísticos em que tais crianças estão inseridas. Isto também pode ser o motivo das diferenças de desempenho encontradas entre os adultos universitários e os que cursaram até a 5 . $^{\text {a }}$ série do ensino fundamental, na segunda questão do Estudo 2. A este respeito, outros trabalhos demonstram que adultos com pouca escolarização compreendem certos termos com menos facilidade do que universitários (ver Dias, 2000; Dias, Roazzi, O’Brien \& Brooks, 2003; Gonçalves \& Dias, 2003). 
Assim, concordamos com as conclusões propostas por Bowerman e Choi (2001, p.505) de que "As predisposições perceptuais e conceituais não lingüísticas para espaço não formam diretamente as categorias semânticas das crianças, mas somente na interação com a estrutura semântica da língua que está sendo adquirida.” (grifo nosso).

Houve, entretanto, certa equivalência entre as respostas das crianças que haviam adquirido tais habilidades, se comparados os Tipos de Escolas quanto aos termos "tirar de" e "tirar de dentro de", ou seja, aos 3 anos de idade foi observado considerável quantidade de acertos tanto das crianças de escolas particulares quanto das crianças de escolas públicas. Isto pode ser influência da presença destes termos específicos no cotidiano de tais crianças, como também dos adultos, o que pode favorecer a compreensão e aquisição dos mesmos.

\section{Referências}

Behl-Chadha, G.P.D. \& Eimas, P. (1995). Infant categorization of left-right spatial relations. British Journal of Developmental Psychology, 13, 69-79.

Bowerman, M. (1976). Semantic factors in the acquisition of rules for word use and sentence construction. In D. Morehead \& A. Morehead (Eds.), Directions in normal and deficient child language (pp.99-179). Baltimore: University Park Press.

Bowerman, M. (1978). The acquisition of word meaning: an investigation into some current conflicts. In M. Waterson \& C. Snow (Eds.), The development of communication (pp.263-287). New York: John Wiley.

Bowerman, M. (1996). Learning how to structure space for language: A crosslinguistic perspective. In P. Bloom, M.A. Peterson, L. Nadel, \& M.F. Garret (Eds.), Language and space (pp.385-436). Cambridge, MA: MIT Press.

Bowerman, M. (2000). Where do children's word meaning come from? Rethinking the role of cognition in early semantic development. In L.P. Nucci, G.B. Saxe, \& E. Turiel (Eds.), Culture, thought and development (pp.199-230). Mahwah, New Jersey: Lawrence Erlbaum.

Bowerman, M. \& S. Choi (1994, janeiro). Linguistic and nonlinguistic determinants of spatial semantic development. Trabalho apresentado no Paper presented at the Boston University Conference on Language Development, Boston, MA.

Bowerman, M. \& S. Choi (2001). Shaping meanings for language: universal and language-specific in the aquisition of spacial semantic categories. In M. Bowerman \& S.C. Levinson (Eds.), Language acquisition and conceptual development (pp.475-511). Cambridge, UK, Cambridge University Press.

Bowerman, M., de Léon, L. \& Choi, S. (1995). Verbs, particles, and spatial semantics: Learning to talk about spatial actions in typologically different languages. In E.V. Clark (Eds.), The proceedings of the 27th Annual Child Language Research Forum (pp.101-110). Stanford CA: Center for the Study of Language and Information.

Bowerman, M. \& Pederson, E. (1992, dezembro). Cross-linguistic perspectives on topological spatial relationships. Trabalho apresentado no Annual meeting of the American Antropological Association, San Francisco, CA. In preparation. Cross-linguistic perspectives on topological spatial relationships.
Braine, M.D.S. (1976). First word combinations. Monographs of the Society for Research in Child Development, 41 (1, Serial n. ${ }^{\circ}$ 164).

Brown, R. (1973). A first language: The early stages. Cambridge, MA: Harvard University Press.

Ceci, S. \& Roazzi, A. (1994). The effects of context on cognition: Portraits from Brazil. In R. Sternberg (Ed.), Mind in context: Interactionist perspectives on human intelligence (pp.74-101). Cambridge: Cambridge University Press.

Choi, S. (1997). Language-specific input and early semantic development: evidence from children learning Korean. In D.I. Slobin (Ed.), The crosslinguistic study of language acquisition (Vol.5, pp.111-133). Mahwah, NJ: Lawrence Erlbaum.

Choi, S. \& Bowerman, M. (1991). Learning to express motion events in english and Korean: The influence of language-specific lexicalization patterns. Cognition, 41, 83-121.

Clark, H.H. (1973). Space, time, semantics, and the child. In Moore, T.E. (Ed.), Cognitive development and the acquisition of language (pp.27-63). New York: Academic Press.

Dias, M.G.B.B., Morais, E.P., \& Pessoa, M.C. (1995). Dificuldade na compreensão de textos: uma tentativa de remediação. Arquivos Brasileiros de Psicologia, 47, 13-22.

Dias, M.G.B.B (2000). Dificuldades com inferências inválidas entre adultos: tentativa de superação. Psicologia: Reflexão \& Crítica, 13, 391-397.

Dias, M.G.B.B., Roazzi, A., O’Brien, D.P., \& Brooks, P.J. (2003). "Se" na perspectiva da Teoria da Lógica Mental: estudos empíricos em crianças e adultos. Psychologica, 32, 285-299.

Dias, M.G.B.B. \& Vanderlei, (1999). A habilidade para diferenciar se de quando. Psicologia: Reflexão \& Crítica, 12, 195-208.

Gibson, E.J. \& E.S. Spelke. (1983). The development of perception. In H. Flavell \& E.M. Markman (Eds.), Mussen handbook of child psychology: Cognitive development (Vol. 3; pp.1-76). New York: John Wiley.

Gonçalves, F. \& Dias, M.G.B.B. (2003). Coerência textual: Um estudo entre jovens e adultos. Psicologia Reflexão \& Crítica, 16 , 29-40.

Johnston, J.R. (1985). Cognitive prerequisites: The evidence from children learning English. In D.I. Slobin (Ed.), The crosslinguistic study of language acquisition. Theoreticalissues (Vol. 2; pp.9611004). Hillsdale, NJ: Lawrence Erlbaum.

Lins e Silva, M.E, \& Spinillo, A.G. (1998). Uma análise da escrita de histórias por alunos de escolas públicas e particulares. Revista Brasileira de Estudos Pedagógicos(INEP), 193(79), 5-16.

Lins e Silva, M.E. \& Spinillo, A.G. (2000). A influência de diferentes situações de produção na escrita de histórias. Psicologia Reflexão E Crítica, 13, 337-350.

Moro, M.L.F. (1991). Interações sociais e construção do conhecimento. Psicologia: Teoria e Pesquisa, 7, 215-227.

Needham, A. \& R. Baillargeon (1993). Intuitions about support in 4.5-month-old infants. Cognition, 47, 12 1-148.

Nelson, K. (1974). Concept, word, and sentence: interrelations in acquisition and development. Psychological Review, 81, 267-285.

Piaget, J. (1954). The construction of reality in the child. New York: Basic Books.

Piaget, J. \& B. Inhelder. (1956). The child's conception of space. London: Routledge \& Kegan Paul.

Roazzi, A. (1996). O papel da experiência, do significado e da representação no desenvolvimento e avaliação de habilidades cognitivas. In M.G. Dias \& A.G. Spinillo (Eds.), Tópicos em psicologia cognitiva (pp.228-269). Recife: Editora Universitária da UFPE. 
Roazzi, A. \& Bryant, P.E. (1992). Social class, context and cognitive development. In P. Light \& G. Butterworth (Eds.), Context and cognition: ways of learning and knowing (pp.14-27). Herts: Harvester \& Wheatsheaf Press.

Sinha, C., Thorseng, L.A. Hayashi, M., \& Plunkett, K. (1994). Comparative spatial semantics and language acquisition: Evidence from Danish, English, and Japanese. Journal of Semantics, 11, 253-287.

Slobin, D.I. (1970). Universals of grammatical development in children. In G.B. Flores D’Arcais \& W.J.M. Levelt (Eds.), Advances in psycholinguintics (pp.174-186). Amsterdam: NorthHolland.

Slobin, D.I. (1973). Cognitive prerequisites for the development of grammar. In C.A. Ferguson \& D.I. Slobin (Eds.), Studies of child language development (pp.175-208). New York: Holt, Rinehart \& Winston.

Spelke, E.S., Breinlinger, K., Macomber, J., \& Jacobson, K.(1992). Origins of knowledge. Psychological Review, 99, 605-632.
Spinillo, A.G. \& Pratt, C. (2002). Text production and metalinguistic awareness for text genres in children of different social backgrounds. Em $8^{\text {th }}$ International Conference of the European Association for Research on Learning and Instruction, Stafford (pp. 114-114). Earli Sig Writing conference, Writing 02 - Stafford: Staffordshire University.

Talmy, L. (1976). Semantic causative types. In M. Shibatani (Ed.), Syntax and semantics: The grammar of causative constructions (Vol.6, pp. 43-116). New York: Academic Press.
Submissão: 04/09/2003 $1^{a}$ revisão: 23/06/2004 Última revisão: 30/09/2004 Aceite final: 22/11/2004 